\title{
Ascites as a Symptom of a Rotavirus Infection-Case Report
}

\author{
Sabina Więcek*, Urszula Grzybowska-Chlebowczyk, Halina Woś \\ Department of Paediatrics, Medical University of Silesia, Katowice, Poland \\ Email: ${ }^{\text {sabinawk@wp.pl }}$
}

Received 7 March 2014; revised 7 April 2014; accepted 17 April 2014

Copyright (C) 2014 by authors and Scientific Research Publishing Inc.

This work is licensed under the Creative Commons Attribution International License (CC BY). http://creativecommons.org/licenses/by/4.0/

(c) () Open Access

\begin{abstract}
Rotaviruses (RV) are the most common cause of acute diarrhoea in children. The course of RV infections may vary from a mild to a serious course of diarrhoea with significant disturbances to the water-electrolyte and acid-base homeostasis and complications requiring hospitalisation. There are known cases of postinfectious enteropathy and severe cases may involve a complete villous atrophy and temporary intolerance to lactose in the course of rotavirus infection. Opinions on the changes in the permeability of the mucous of the small intestine in the result of ongoing inflammation are largely diverse. This study presents a very rare complication of a rotavirus infection which is ascites in a 3-month infant. It seems that the pathomechanism of ascites in presented patient is very complex and affected by other factors such as nutritional disorders, including hypoproteinemia and hypoalbuminemia and immunological factors.
\end{abstract}

\section{Keywords}

Rotavirus Infection, Ascites, Children

\section{Introduction}

Rotaviruses are the most common cause of acute diarrhoea in children. This infection often results in hospitalisation and is at the same time a source of infections within hospitals, children's homes, schools and kindergartens. The course of RV infections may vary from a mild to a serious course of diarrhoea with significant disturbances to the water-electrolyte and acid-base homeostasis and complications requiring hospitalisation. 30\% of infants with rotavirus infection may manifest symptoms from the nervous system, mainly as behavioural changes like irritability, apathy and or spasms. Literature on the subject suggests a possible connection between rotavirus infection and the following: Reye's syndrome, haemolytic-uraemic syndrome, pancreatitis, sudden in-

*Corresponding author.

How to cite this paper: Więcek, S., Grzybowska-Chlebowczyk, U. and Woś, H. (2014) Ascites as a Symptom of a Rotavirus Infection-Case Report. Advances in Infectious Diseases, 4, 73-76. http://dx.doi.org/10.4236/aid.2014.42012 
fant death syndrome and Kawasaki disease [1]-[3]. In more than 40\% of children with acute diarrhoea of rotavirus etiology, an elevated level of aminotransferase, in particular of aspartate aminotransferase, can be observed. In most cases an elevated level of aminotransferases is transitory and normalises idiopathically during observation [4]-[6]. A co-relation has been proven between rotavirus infection and necrotising enterocolitis in premature infants and patients with immunological disorders [7] [8]. The occurrence of intussusceptions within the gastrointestinal tract of a frequency higher than populational has also been observed in children, especially the youngest ones with RV diarrhoea. However, there is no data in the literature which would show a connection between ascites and rotavirus infection.

\section{Case Study}

A girl from a fifth, multiple pregnancy (Twin 1), delivered in the $38^{\text {th }}$ week by caesarean section with the birth weight of $2050 \mathrm{~g}$, length $47 \mathrm{~cm}$ and 9/10 on the Apgar scale was admitted into the Department of Paediatrics at the age of 3 months due to diarrhoea which had started 7 days before. The girl was passing about 10 stools per day also with mucus. Additionally, during hospitalisation meconium stools were periodically observed. The history included vomiting of chyme which had started two days before, weight loss of about $200 \mathrm{~g}$ within 2 weeks and a change in the behaviour of the child involving weakness and apathy. Information concerning feeding: the child was fed naturally for 1 week and then with modified milk. So far the child had been treated with amoxicillin for a urinary tract infection. At the same time the twin brother was heavier by about $700 \mathrm{~g}$ despite a comparable birth weight. The girl had been vaccinated with one dose of hepatitis B vaccine and against tuberculosis. Upon admission the patient was in a moderate-severe condition, weak and apathetic. The conclusions of the physical examination included insufficient body weight loss (below $3 \mathrm{pcn}$ ), paleness of the skin, very poorly developed subcutaneous tissue and a distended abdomen. Laboratory tests revealed anaemia (Hb-9.0 g\%), a lowered level of protein in the blood serum (total protein-45.4 g/l) and a slightly elevated level of C-reactive protein (CRP-11.9 g/l).

Stoll test for Salmonella/Shigella, enterogenic strains of E. coli, Campylobacter and Yersinia were negative. Immunoenzymatic stool test for rotavirus was positive. The parameters of the acid-base homeostasis, electrolytes and coagulation were normal. Abdominal ultrasound revealed fluid in the peritoneal cavity of up to $2.5 \mathrm{~cm}$ and in Morison's pouch of up to $1.2 \mathrm{~cm}$. Observations conducted the following days revealed that the volume of fluid had increased to about $6 \mathrm{~cm}$ (Figure 1). Apart from that, the abdominal organs, as shown in the ultrasonography, also with the Doppler option, were normal.

As gastrointestinal obstruction was suspected, the following examinations were conducted: plain abdominal $\mathrm{x}$-ray was performed, which revealed only dilated intestinal loops filled with fluid content, and barium enema (Neuhauser's method), thus excluding Hirschprung's disease. The infant was consulted by a surgeon several times.

The following were excluded: infection caused by cytomegalovirus, urinary tract infection, sepsis, hypothyroidism and diseases of the suprarenal glands. An elevated level of total immunoglobulin $\mathrm{E}$ in the blood serum (81.4 U/ml) was also observed. Levels of immunoglobulins A, M and G were normal. Due to an increased level of acid steatocrit, the test of chlorides in sweat was performed with the Wescor method. A genetic test excluded cystic fibrosis.

The differential diagnosis also involved and later excluded the following:

- gastrointestinal tract perforation

- sepsis (negative bacteriological test of blood)

- circulatory failure, cardiovascular diseases, following several consultations with a cardiologist. Only hemodynamically insignificant PDA and FoA with a left-to-right shunt was concluded.

- liver diseases including thrombotic lesions-normal Doppler examination of the portal system

- hypoproteinemia in the course of malabsorption-negative antibodies for enterocytes

- hypoproteinemia in the course of nephrotic syndrome

- cancers

- disorders of cellular and humoral immunity

Treatment included antibiotic therapy, parenteral hydration and balancing of water-electrolyte and acid-base homeostasis. Parenteral nutrition, albumin infusion and diuretics (spironolactone, furosemide) were also applied. Nutrition involved amino acid elementary formula. That resulted in a gradual improvement of the general condition, normalisation of the stools and improvement in the results of laboratory tests. 

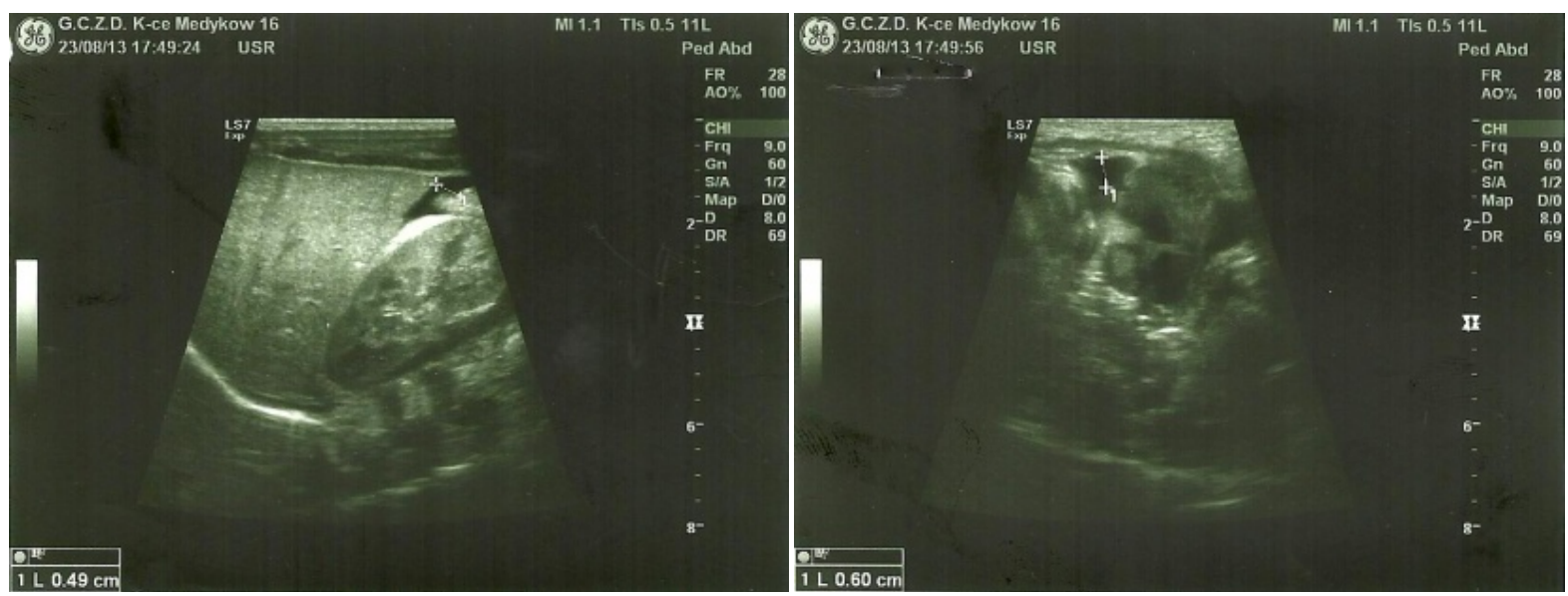

Figure 1. Abdominal ultrasonography of the patient.

After a month the infant was admitted to a local hospital again due to acute diarrhoea, but of a milder course. The abdominal ultrasound showed only a trace of interloped fluid. The stool test for RV antigen was again positive. Currently the girl is in a good general condition. She remains a patient of the gastroenterological department, passes normal stools and her abdominal laboratory tests and ultrasounds are normal.

\section{Overview and Discussion}

Serious de-hydration, disturbances to the water-electrolyte and acid-base homeostasis and neurological disorders such as febrile convulsions, encephalitis and cerebellitis are complications often mentioned in the course of rotavirus infection. There are known cases of postinfectious enteropathy and severe cases may involve a complete villous atrophy and temporary intolerance to lactose [1]-[3]. Opinions on the changes in the permeability of the mucous of the small intestine in the result of ongoing inflammation are largely diverse. A number of authors confirm this theory. In those situations secondary hypoproteinemia and hypoalbuminemia, which theoretically may lead to ascites, may occur [9]-[11]. It is possible that our patient experienced hypoproteinemia resulting from enteropathy following rotavirus infection. However, there have been no reports in the literature on ascites as a complication following the infection. The role of rotavirus infection in the etiology of autoimmune diseases, including Type 1 diabetes and coeliac disease is also unclear. Probably this virus may play a role in the initiation of autoimmunological processes (the role of molecular mimicry of RV). Additionally, it is worth noticing the similarity between the outer-layer proteins of the virus (VP7) and the epitopes of the antibodies for protein-tyrosine-phosphatase and for glutamic acid decarboxylase [11] [12]. Antibodies for enterocytes in the girl's blood serum were absent.

An additional contributor in the case of our patient was the complicated history of her pregnancy and delivery as multiple pregnancy and low birth weight may have contributed to protein, albumin and immunoglobin deficiencies. It has been proved that rotavirus infection in persons with an impaired immune system, including premature infants may cause systemic infection affecting many organs-lungs, kidneys, the central nervous system, the liver and the syndrome of intravascular coagulation as a result of general viraemia. The effect of RV infection in premature infants on the occurrence of necrotising enterocolitis (statistically significant difference was $66 \%$ vs 30\%) has been shown [7] [8]. Ascites in infants in most often related to liver diseases, including metabolic diseases. In our patient the parameters of damage to liver cells and cholestasis were normal. Additionally the following were excluded: cytomegalovirus infection, general bacterial infections, diseases of thyroid and suprarenal gland (the level of cortisol) and alpha-1 antitrypsin. Metabolic tests of the following: the level of lactic acid, the profile of organic acids in urine and tandem mass of MS and the level of ammonia were also normal. The girl has had multiple neurological consultations and remains a patient of a specialist clinic. Normal psychomotor development, clinical picture and results of tests do not indicate lysosomal diseases. The subject literature brings a number of reports mentioning the relation between ascites in infants and circulatory failure, especially of the right ventricle [13]-[15]. Our patient underwent three echocardiographs which were normal and therefore all abnormalities of the cardiovascular system were excluded. There are studies on the co-relation be- 
tween eosinophilic gastroenteritis and ascites [10] [16]. However, those patients are older and had eosinophilia observed in their peripheral blood. Due to the serious condition of our patient, endoscopic tests were not conducted. Another component which is conducive to hypoproteinemia may be food allergy. An elevated level of total immunoglobin $\mathrm{E}$ in the blood serum and intensified diarrhoea made us include amino acid elementary formula. Maybe the pathomechanism of ascites in the patient was of a complex nature. On the one hand it may have been affected by the prematurity and immaturity, but on the other hand it may have been a food allergy and everything was triggered by a rotavirus infection.

\section{Conclusion}

Rotavirus infection, especially in patients with accompanying other diseases may lead to systemic complications, including ascites. However, it seems that the pathomechanism of ascites is very complex and affected by other factors such as nutritional disorders, including hypoproteinemia and hypoalbuminemia and immunological factors.

\section{References}

[1] Bruijning-Verhagen, P., Sankatsing, V., Kunst, A., et al. (2012) Rotavirus-Related Hospitalizations Are Responsible for High Seasonal Peaks in All-Cause Pediatric Hospitalizations. Pediatric Infectious Disease Journal, 31, 244-249. http://dx.doi.org/10.1097/INF.0b013e31826a5ba1

[2] Desai, R., Esposito, D., Lees, C., Goodin, K., et al. (2011) Rotawirus-Coded Deaths in Children United States 19992007. Pediatric Infectious Disease Journal, 30, 986-988. http://dx.doi.org/10.1097/INF.0b013e318220fe20

[3] Hagbom, M., Sharma, S., Lundgren, O. and Svensson, L. (2012) Towards a Human Rotavirus Disease Model. Current Opinion in Virology, 2, 408-418. http://dx.doi.org/10.1016/j.coviro.2012.05.006

[4] Kacerka, A., Wójcik, K., Kuydowicz, J., et al. (2009) An Evaluation of the Relationship between Rotavirus Diarrhoea and Bacterial Infection and Acute Hepatitis in Children. Polish Gastroenterology, 16, 446-448.

[5] Kawashima, H., Ishii, H., Ioi, H., et al. (2012) Transaminase in Rotavirus Gastroenteritis. Pediatrics International, 54, 86-88. http://dx.doi.org/10.1111/j.1442-200X.2011.03532.x

[6] Więcek, S., Grzybowska-Chlebowczyk, U., Stawicka-Ociepka, E. and Woś, H. (2011) Hipertransaminazemia w przebiegu ostrej biegunki u dzieci. Forum Medycyny Rodzinnej, 6, 491-498.

[7] De Villiers, F.P. and Driessen, M. (2012) Clinical Neonatal Rotavirus Infection: Association with Necrotizing Enterocolitis. South African Medical Journal, 6, 620-624.

[8] Tan, R., Lee, J., Biswas, A. and Amuntha, C. (2014) Ascites Anemia and Intestinal Atresia. Journal of Perinatology, 34, 78-80. http://dx.doi.org/10.1038/jp.2013.124

[9] Mouavas, V., Dede, O., et al. (2012) Diagnosis and Management of Congenital Neonatal Chylous Ascites. Hippokratia, 16, 175-180.

[10] Liu, L., Liang, X., Huang, H. and Jia, L. (2013) Clinical Features of Eosinophilic Gastroenteritis with Ascites. Zeitschrift fur Gastroenterologie, 51, 638-642. http://dx.doi.org/10.1038/jp.2013.124

[11] Rostami-Nejad, M., Rostami, K., Sanaei, M., et al. (2010) Rotavirus and Coeliac Autoimmunity among Adults with Non-Specific Gastrointestinal Symptoms. Saudi Medical Journal, 3, 891-894.

[12] Volta, U. (2009) Pathogenesis and Clinical Significance of Liver Injure in Celiac Disease. Clinical Reviews in Allergy and Immunology, 36, 62-70.

[13] Chen, C., Lin, M., Wu, E., Lu, L., et al. (2005) Clinical Manifestations and Outcomes of Constrictive Pericarditis in Children. Journal of the Formosan Medical Association, 104, 402-407.

[14] Cochran, W., Klish, W., Brown, M., Lyons, J. and Curtis, T. (1985) Chylous Ascites in Infants and Children: A Case Report and Literature Review. Journal of Pediatric Gastroenterology and Nutrition, 4, 668-673. http://dx.doi.org/10.1097/00005176-198508000-00031

[15] Codurache, C., Johnsrude, C., Bryant, K. and Recto, M. (2008) Ascites Secondary to Indolent Pacemaker Infection in a Fontan Patient. Texas Heart Institute Journal, 35, 342-344.

[16] Gamarra, Y., Nova, M. and Herrera, A. (2011) Eosinophilic Gastroenteritis with Ascites: Clinical Case Report. Rev.Gastroenterol.Peru, 31, 173-177. 